\title{
FACES FEMININAS NAS BIOGRAFIAS DE PLUTARCO
}

Maria Aparecida de Oliveira Silva*
* Doutora pela

Universidade de São Paulo

RESUMO: Embora tenha escrito mais de cinquenta biografias, Plutarco de Queroneia não compôs sequer uma que tratasse da vida de uma mulher ilustre. Portanto, nosso objetivo neste artigo é sistematizar informações esparsas sobre o papel das mulheres na sua obra biográfica de Plutarco.

PALAVRAS-CHAVES: Plutarco; biografia antiga; gênero.

\section{WOMEN IN THE BIOGRAPHIES OF PLUTARCH}

ABSTRACT: Although Plutarch of Chaeronea had written over fifty biographies, not even one has been written about the life of an illustrious woman. Therefore, our aim in this paper is to systematize sparse information about the role of women in his biographical work.

KEYWORDS: Plutarch, ancient biography, gender.

$1 \begin{aligned} & \text { ausência de biografias femininas na obra de } \\ & \text { Plutarco evidencia o desinteresse dos antigos pelos } \\ & \text { feitos de uma mulher em especial, demonstrando }\end{aligned}$ que a política é um espaço reservado exclusivamente ao homem, ainda que encontremos mulheres que de alguma forma interferiram nos assuntos citadinos (Buszard: 2010, 83-83). Desse modo, as mulheres aparecem em segundo plano em sua narrativa, como notou Le Corsu (1996, 32). Nosso autor pouco fala sobre elas, porém isso não significa que as mulheres não tenham desempenhado um papel importante no desenrolar de certos acontecimentos. Quem são essas mulheres e qual a participação delas na narrativa das cinquenta biografias preservadas de Plutarco? Essas são as indagaçóes que norteiam este artigo. 
1. Loman analisa a participação feminina em campanhas militares, mulheres que atuam somente na defesa de seus territórios (Loman: 2004, 34-54).

\section{As CORAJOSAS}

É interessante notar que Plutarco narra breves episódios em que as mulheres foram decisivas em momentos importantes das biografias de suas personagens. A atuação delas surge então como demonstração de coragem, muitas vezes advinda de um sentimento de superação de sua própria condição inferior dentro de um contexto dominado por homens. Como veremos, tais mulheres são tomadas por um sentimento de compaixão, outras levadas por um sentimento de justiça, mas todas trazem em comum o ímpeto de proteção, quer de si mesmas, quer de um homem em perigo, quer de sua cidade. ${ }^{1}$

Ao ser capturado por Alexandre, o tirano de Feras, Pelópidas, recebeu a visita de uma mulher chamada Tebe, filha de Jasão e esposa do tirano, encontro que Plutarco assim descreve:

Tebe, filha de Jasão, mulher de Alexandre, quando ouviu junto aos guardas sobre o desafio e a nobreza de Pelópidas, desejou conhecer o homem e conversar com ele. Após ter ido até ele, como mulher, não percebeu logo a magnitude de seu caráter em tamanho infortúnio, mas pelo corte dos cabelos, pela vestimenta e por sua condição reconheceu a precariedade e que não lhe convinha sofrer por sua glória, quando caiu em prantos. Primeiro, ignorando quem seria a mulher, Pelópidas ficou admirado. Quando soube, chamou-a pelo nome do pai, pois foi companheiro e amigo de Jasão. E aquela lhe dizia: "Apiedo-me por tua mulher", pelo que ele respondeu: "também eu por ti que, não estando acorrentada, suportas Alexandre". Assim, o discurso, de algum modo, tocou a mulher, pois estava pressionada pela crueldade e violência do tirano, depois de outra licenciosidade, e de ter feito seu favorito o irmão mais novo dela. Por isso, continuamente frequentava Pelópidas e falava-lhe abertamente sobre as coisas que sofria, preenchendo o peito de desprezo e animosidade contra Alexandre. (Vida de Pelópidas, XXVIII, 5-10)

O registro de Plutarco sobre a morte do tirano é rico em detalhes, assemelhando-se a uma pequena peça teatral dentro de sua narrativa, em que os sentimentos das personagens recebem colorações mais intensas para a dramaticidade da cena, ao mesmo tempo em que envolve o 
leitor no relato e o torna convicto de que o ato foi motivado mais pelo senso de justiça que pela traição. É interessante notar que Plutarco também enfatiza a limitação de raciocínio de Tebe, "como mulher", pois sua compreensão dos acontecimentos está relacionada à sua percepção sensorial em detrimento da lógica racional. Igualmente, Plutarco demonstra que a mulher é fortemente influenciável pelo discurso, pois revela que, além de ser comandada pelo sentimento de ódio nutrido por ele, Tebe também seguiu o conselho dado por Pelópidas, de que ela não deveria temer a tirania. Após esclarecer os motivos que levaram ao complô de Tebe com seus irmãos para o assassinato de Alexandre, ${ }^{2}$ Plutarco interpreta o ocorrido como resultado de um castigo divino, em virtude do tratamento que o tirano dispensou a Pelópidas, como se tratasse da nêmesis divina, muito comum nas tragédias (Vida de Pelópidas, XXXV, 5).

Na campanha malsucedida de Pirro contra Esparta, nosso autor destaca a coragem de Arquidâmia, a espartana que se recusa a fugir para Creta, unindo-se às demais mulheres: todas permanecem ao lado dos homens e atuam na escavação de um fosso para proteger a cidade; depois de findo o trabalho, elas se juntam a eles na linha de frente da batalha (Mossman: 2005, 498-517). Segundo Plutarco, citando Filarco e Jerônimo, as mulheres exortavam os homens à batalha com as seguintes palavras: "como é doce vencer sob os olhos da pátria, e glorioso morrer nas mãos das suas mães e mulheres, dignamente tombando por

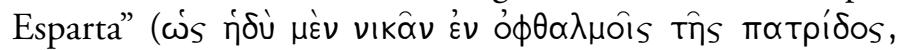

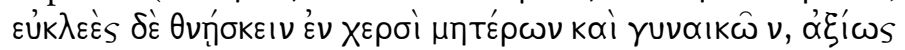

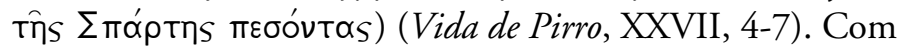
esse episódio, Plutarco reafirma a coragem das espartanas, que ele já assinalara em Ditos das Mulheres Espartanas (240C242D), onde as mulheres demonstram seriedade e rigor no cumprimento de seus deveres, amor à cidade acima de qualquer laço de parentesco, uma administração equilibrada do seu lar, sem luxos ou futilidades, e grande apreço por sua liberdade. ${ }^{3}$

$\mathrm{Na}$ biografia de Alexandre, Plutarco relata o saque dos trácios em Tebas, destacando que alguns soldados e o seu general invadiram a casa de Timocleia e que, por ela ser
2. Jacquin redigiu um interessante artigo sobre o papel da mulher em governos tirânicos (2011, 1-22). 
3. A coragem e a determinação das mulheres espartanas são analisadas por Redfield (1977-1978, 146-161).

4. Mossman sugere que a história de Timocleia é mais um elemento trágico que Plutarco insere em sua narrativa sobre a destruição de Tebas $(1988,86)$.

5. Sobre esse episódio da biografia de Coriolano, consultar Russell, 1963, 21-28.

6. Note-se que há duas Valérias, uma irmã e a outra filha de Publícola, ambas corajosas. muito bela e de atraente porte, logo foi violada pelo seu comandante. ${ }^{4}$ Após concluir o ato desonroso, o general lhe perguntou onde escondia seu ouro e sua prata, quando foi atraído por ela para a borda de um poço, sob a alegação de que ali escondera sua riqueza; então ela o empurrou para dentro do poço e o cobriu de pedras. Por isso, foi acorrentada e levada à presença de Alexandre para que fosse julgada. Ao vê-la, Alexandre percebeu que se tratava de uma mulher de boa estirpe e muito corajosa, pois não demonstrava qualquer medo; tais qualidades o levaram a admirá-la e a absolvê-la (Vida de Alexandre, XII, 1-6).

$\mathrm{Na}$ biografia do romano Publícola, nosso autor relata o episódio em que Tarquínio planeja atacar Valéria, filha de Publícola, que se banhava ao lado de Clélia e outras moças. Embora as moças tenham sido socorridas por Porsena e seu filho, elas demonstraram coragem e resistiram bravamente correndo entre os soldados em luta (Vida de Publícola, XVIII, 3 e XIX, 1-9).

Coriolano decide atacar Roma, mas é interceptado por algumas mulheres que lhe suplicam para abandonar o seu intento. A primeira é a esposa de Coriolano, irmã de Publícola, que Plutarco assim descreve: "Valéria tinha reputação e honra na cidade, parecendo em vida que não

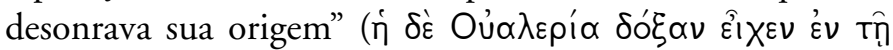

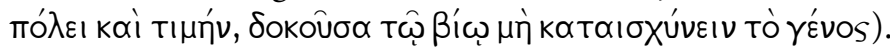
Segundo nosso autor, tomada por uma inspiração divina

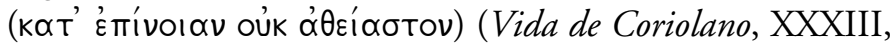
1-3), ${ }^{5}$ Valéria $^{6}$ convoca as mulheres para defender a cidade, implorando a Coriolando a não invadir Roma. Plutarco cita ainda os nomes de Volúmnia, mãe de Coriolano, e de Virgília, sua irmã. Elas então ao lado dos filhos do general e de outras mulheres formam uma linha de frente e passam a suplicar com palavras e gestos de carinho para que Coriolano e os volscos não tomassem a cidade, de tal sorte que a invasão não ocorreu (XXXIII a XXXVII).

Apesar de os dois exemplos a seguir não serem de mulheres que demonstraram coragem no aspecto guerreiro, elas são corajosas pelas suas virtudes. Segundo Plutarco, Fócion teve duas mulheres, mas não cita o nome de nenhuma delas. Sobre a primeira, sabia-se apenas que era irmã do escultor 
Cefisodoro; já sobre a segunda, afirma que "os atenienses tinham um discurso sobre sua temperança e simplicidade"

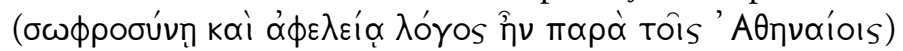
(Vida de Fócion, XIX, 1-2).

Árato sobreviveu ao morticínio promovido por Abântida, aspirante à tirania, que eliminou todos os seus prováveis concorrentes, incluindo seus filhos. Árato contava então com sete anos de idade, quando em fuga entrou por acaso na residência da irmã de Abântida e esposa de Profanto, Sosa, descrita por Plutarco como uma mulher generosa; crente que um deus o tinha conduzido a sua casa, ela o socorreu e o enviou para Argos (Vida de Árato, II, 1-4).

AS MÃES

As figuras femininas que exercem sua maternidade aparecem em episódios nos quais trazem em comum a tentativa de proteção de seus filhos, ou seja, não se trata de mulheres passivas, mas que atuam e interferem nos acontecimentos. Há ainda as mães que são dotadas de uma certa premonição sobre as características físicas ou morais de seus rebentos, revelaçóes que lhes são mostradas por intermédio de sonhos. ${ }^{7}$

$\mathrm{Na}$ biografia do herói fundador ateniense, aparece a personagem feminina de Etra, sua mãe, que "ocultava a

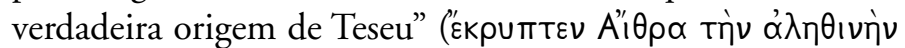

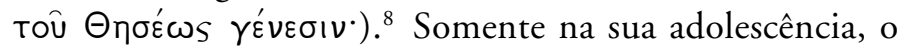
jovem soube por Etra que era filho de Egeu, rei de Atenas, no célebre episódio da retirada da espada e das sandálias de seu pai escondidas em uma pedra. Então, portando os objetos de reconhecimento deixados por seu pai, Teseu decide viajar para Atenas e reivindicar seu direito ao trono (Vida de Teseu, VI, 1-3).

Agariste, neta de Clístenes e mãe de Péricles, sonhou que dava à luz a um leão com cabeça alongada; conforme nosso autor, para esconder seu defeito físico, o político ateniense sempre era retratado usando seu capacete, e que, por essa característica peculiar de sua aparência, "os poetas áticos o chamavam de cabeça de cebola" (oi $\delta$ ' 'Aтtıkoi moıntai

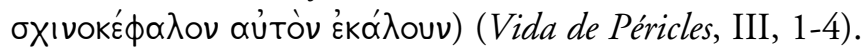

7. Conforme notou Bremmer, Plutarco se esforça por revelar os nomes das mães de suas personagens, em especial, nas biografias gregas; no entanto sua dificuldade está na tradição dos antigos gregos de evitar citar os nomes das mulheres (1981, 425-426).

8. Russell afirma que os heróis de Plutarco trazem características muito semelhantes às dos homéricos, como a proteção das mães, um caráter corajoso e violento (1982, 24-34). 
9. Nas biografias plutarquianas, Filipe é o único pai a ter tido uma visão sobre o filho antes de nascido; talvez isso se explique por uma possível influência do sonho de Olímpia sobre ele.

10. De acordo com Carawan, a biografia plutarquiana de Marcelo é devedora da narrativa de Titio Lívio (1984-1985, 131-141).
A jovem mãe de Alexandre, o Grande, sonhou que trovejava muito e que um raio caía sobre o seu ventre formando um grande fogo que se espalhava por todo o quarto. Passado um tempo, Filipe também tivera a visão de que Olímpia trazia em seu ventre um selo com a marca de um leão; desde então, os adivinhos da corte o aconselharam a vigiar sua esposa. ${ }^{9}$ Telmesso foi o único adivinho a dizer que Olímpia estava grávida e que daria à luz a "um filho

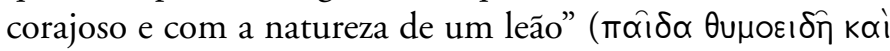

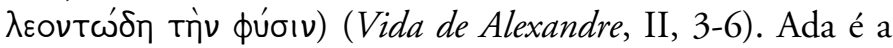
mulher a quem Alexandre tratava como mãe; de tanto honrála, tornou-a rainha da Cária. Nosso autor conta ainda que ela enviava acepipes e guloseimas diariamente a Alexandre, e que certa vez ofereceu-lhe cozinheiros de várias especialidades, mas a frugalidade do rei o fez recusar a oferta, dando-lhe como resposta que os melhores cozinheiros já estavam em seu grupo de serviçais (XXII, 7-10).

A vestal Ília ou Sílvia é a mãe de Rômulo e Remo, dado que explica a exposição de seus filhos na floresta e sua criação por uma loba (Vida de Rômulo, III, 1-6). Nos capítulos IV e V, nosso autor afirma que alguns romanos cultuavam Larência, por acreditarem que ela teria criado os gêmeos, não a loba.

No último capítulo da biografia de Marcelo, ${ }^{10}$ nosso autor afirma que sua família sustentou a glória de seu nome, contando que "para sua honra e memória, sua mãe Otávia lhe dedicou sua biblioteca, e que Augusto deu o nome de

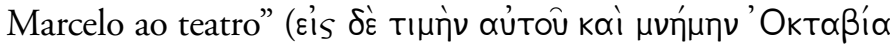

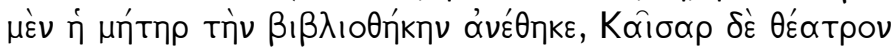

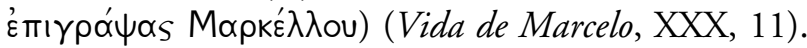

\section{AS DOMINADORAS}

A dominação feminina nas biografias de Plutarco acontece por duas formas: a primeira ocorre por conta do poder econômico, pois são mulheres ricas que exercem influência sobre os homens públicos detentores de cargos importantes no cenário político. Outra forma de dominação se estabelece pelo amor, mais relacionado a uma paixão desenfreada que retira o raciocínio do amante e o torna uma 
espécie de súdito da mulher amada, sendo um mero coadjuvante na execução de todos os seus desejos. ${ }^{11}$

O rei Agesilau desposou Cleora, com quem teve duas filhas, Eupólia e Preuga (Vida de Agesilau, XIX, 6); sua irmã Cinisca foi vencedora de uma corrida de quadrigas em Olímpia, fato que evidencia a riqueza particular dela, assim como a projeção de uma mulher espartana no cenário grego. ${ }^{12}$ Sobre a vitória de Cinisca, Plutarco comenta "que não foi própria de nenhuma virtude, mas a vitória da riqueza

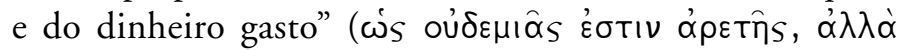

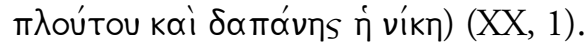

O rei Ágis de Esparta, pelas informações de nosso autor, foi criado na riqueza, uma vez que sua mãe Agesístrata e sua avó Arquidâmia eram "as que mais riquezas haviam

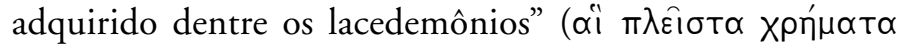

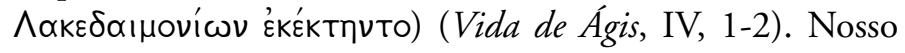
autor lembra que os espartanos sempre consultaram suas mulheres, permitindo-as participar dos assuntos públicos mais que eles nos domésticos. Assim, durante o reinado de Ágis, as mulheres exerciam grande influência por tradição e também porque a maior parte das riquezas da Lacedemônia estava em poder delas. ${ }^{13}$ Como as mulheres eram contrárias à proposta do rei de reinstituir as leis licúrgicas, a cidade permaneceu no caos social, com grandes desigualdades entre ricos e pobres (VII, 1-8). Cleômenes, por sua vez, conseguiu estabelecer algumas mudanças graças à sua mãe Cratesicléia, que aliciou muitos cidadãos com sua riqueza, até mesmo os éforos (Vida de Cleômenes, VI, 1).

Marco Antônio teria sido ultrajado por Dolabela por causa de sua esposa, sua prima, filha do cônsul Caio Antônio (Vida de Antônio, IX, 2); ${ }^{14}$ note-se que Plutarco não cita seu nome. Em seguida, Marco Antônio desposa Fúlvia, ${ }^{15}$ ex-mulher de Clódio, que, segundo nosso autor, "não fiava nem se preocupava com o serviço feminino de cuidar da casa, não julgava digno dominar um homem particular, mas queria governar um governante e comandar um general"

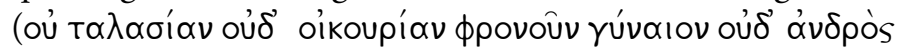

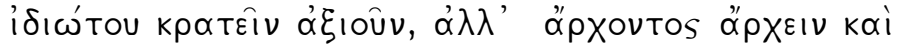

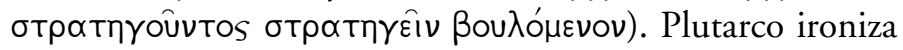
a situação lembrando Cleópatra, pois esta era devedora daquela pelas liçôes de submissão à mulher que Marco
11. Notamos que a paixão avassaladora é alvo de acirradas críticas do nosso autor. Para uma visão mais aprofundada do tema em Plutarco, consultar: Walcot, 1998, 166-187.

12. Para mais detalhes sobre as biografias espartanas e o lugar da mulher em Esparta, consultar: Silva: 2006.

13. Mossé afirma que essa é uma época revolucionária em Esparta, que se inicia com o rei Ágis no século III a.C. e se encerra no II a.C., com a morte de Nábis. Um período no qual a mulher espartana desempenha importante papel político ao lado dos homens. (1991, 138-153).

14. Para uma leitura mais aprofundada da biografia de Antônio, consultar: Wet: 1990, 80-90.

15. Sobre os casamentos de Marco Antônio, consultar: Huzar: 1985-1986, 97-111. 
16. Plutarco conta os episódios amorosos ocorridos entre Marco Antônio e Cleópatra, dos capítulos XXV ao XXX.

17. Embate narrado dos capítulos LXI ao LXXXVI.

18. Após a derrota, Cleópatra comete suicídio

(LXXI, 6-8). Há um artigo interessante sobre esse episódio de Marasco: 1995, 317-325.
Antônio recebeu (X, 4-6).

Na visão de Plutarco, "o amor de Cleópatra o atacou, despertou nele ainda muitas paixões escondidas e silenciadas,

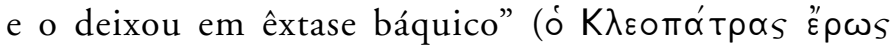

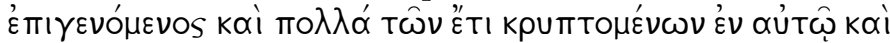

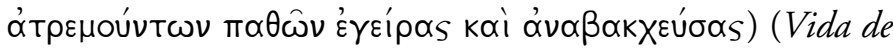
Antônio, XXV, 1-4), completamente entregue aos desejos da rainha do Egito. ${ }^{16}$ Não obstante o amor que nutria por Cleópatra, Marco Antônio retornou a Roma; como era viúvo de Fúlvia, desposou Otávia, irmã de Júlio César, segundo Plutarco, para combater o amor nutrido pela rainha egípcia

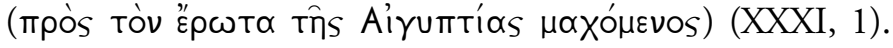
Mas de nada adiantou, pois, depois da guerra contra os partos, Marco Antônio encontrou-se com Cleópatra e se rendeu ao seu amor (LI, 1-3). Quando soube do ocorrido, indignado, Júlio César iniciou os preparativos para a guerra e lutou junto ao Senado pela aprovação da batalha em Ácio; com tudo pronto, avançou contra as tropas de Marco Antônio e Cleópatra, ${ }^{17}$ impingindo-lhes a mais fragorosa derrota. ${ }^{18}$

\section{AS ARDILOSAS}

Como veremos a seguir, os episódios envolvendo mulheres ardilosas estão relacionados a sentimentos de ambição, paixão, ódio e ciúme desmedidos. Nosso autor nos mostra que as mulheres são guiadas não apenas por sentimentos bons como os de compaixão e proteção, mas também por sentimentos maus, e que, quando por eles movidas, realizam atos reprováveis, interferindo no curso dos acontecimentos.

Plutarco narra episódio de Licurgo com sua cunhada, cujo o nome não revela, apenas afirma que ela estava grávida de Carilau, "alegria do povo", o futuro rei de Esparta. Por estar apaixonada pelo legislador, propõe-lhe eliminar o filho de seu irmão, a fim de que se tornar rei em seu lugar. Então, para garantir seu nascimento, Licurgo finge aceitar o plano dela e assim que o menino nasceu, anuncio o nascimento do novo herdeiro ao povo, garantindo o trono para o seu sobrinho (Vida de Licurgo, III, 1-5). 
Filipe desposou Cleópatra já em idade bastante avançada, estimulado por Átalo, o tio da jovem (Vida de Alexandre, IX, 6-9); ambos, segundo Plutarco, vilipendiaram Pausânias, fato que o incitou a assassinar Filipe por pensar que ele fora o responsável por seu prejuízo. Contudo, tal ardil foi imputado à Olímpia, a primeira mulher de Filipe, e Plutarco afirma que até mesmo Alexandre acreditava na culpa de sua mãe. A desconfiança dele levou Olímpia a tratar Cleópatra com muita crueldade, provocando a indignação de seu filho (X, 5-6). Mais tarde, na ausência de Alexandre que estava lutando na Ásia, ambas travaram uma disputa por territórios, cabendo Epiro à Olímpia e a Macedônia à Cleópatra; ao saber disso, Alexandre felicita a mãe pela boa escolha, afirmando que os macedônios não suportavam ser governados por uma mulher (LXVIII, 3-5). Plutarco não dá prosseguimento ao seu relato, mas a resposta de Alexandre nos leva a crer que Cleópatra foi deposta ou morta.

Plutarco conta que Roxane estava grávida quando Alexandre morreu; por isso era venerada pelos macedônios. No entanto, durante sua campanha militar na Ásia, Alexandre havia desposado Estatira, filha de Dario. Enciumada, Roxane envia uma carta a Estatira, fingindo uma aproximação; quando ela e sua irmã chegam, com a cumplicidade de Pérdicas, a mulher ordena a execução das irmãs (LXXVII, 6-7).

Plutarco afirma que a guerra travada por Júlio César contra o Egito era desnecessária, que foi movido somente pelo amor que sentia por Cleópatra. No início, para evitar cair nos braços dela, bebia todas as noites, porém não resistiu e mandou buscar Cleópatra do exílio. Não tardou muito para que a rainha do Egito concebesse um plano para impressionar e conquistar o amor de Júlio César, fato que é descrito assim:

E ela, acompanhada somente de um amigo, o siciliano Apolodoro, embarcou em um pequeno barco ligeiro e chegou ao palácio já anoitecendo; não havendo recurso para passar despercebida, ela mergulhou em roupas de cama e estendeu-se por inteiro, e Apolodoro prendeu as roupas de cama com uma tira de lã e atravessou a porta indo até César. E diz-se que esse foi o primeiro artifício de Cleópatra o apanhou, mostrando-se para ele brilhante, 
e ele foi ainda conquistado por sua conversa e graça, reconcilioua com o irmão, que com ela partilhou o reino. (Vida de César, XLIX, 1-4)

Porque o irmão de Cleópatra uniu-se aos seus inimigos, Júlio César os combateu e, após a sua vitória, entregou o reino a Cleópatra, grávida de seu filho Cesário, partindo para a Síria (Vida de César, XLIX, 9-10).

Nosso autor conta que Parisátis, esposa de Artaxerxes, rivalizava com Estatira, sua outra esposa, visto que a relação deles estava pautada no amor e na confiança. Para saciar seu ódio e sua sede de vingança, Parisátis concebe um plano para envenenar a segunda rainha (Vida de Artaxerxes, XIX, 1-10). Contudo, Artaxerxes sentia uma imensa paixão por sua filha Atossa; quando sua mãe percebeu seu sentimento, por interesses escusos, passou a tratá-la com mais afeição, estimulando o casamento do pai com a filha - Plutarco acrescenta que pai e filha já haviam se relacionado em segredo, bem antes do casamento. No entanto, Artaxerxes se enamorara de sua outra filha, Améstris, com quem se casou, mas manteve seu casamento com Atossa, mesmo quando ela contraiu lepra (XXIII, 1-7).

\section{As CORTESÃS}

19. Pomeroy afirma que as cortesãs atingiram grande popularidade na Atenas clássica, que provinham de diferentes cidades e origens sociais. Havia as que eram escravas e conseguiam comprar sua liberdade, as que eram de camadas inferiores da própria cidade de Atenas, mas a maioria era composta por estrangeiras, sendo Aspásia de Mileto a mais famosa delas. Consultar: Pomeroy: 1995, 57-92.
Várias personagens biografadas por Plutarco sofreram a influência de mulheres que desempenhavam a função de cortesã. ${ }^{19}$ Excetuando Aspásia de Mileto, que exerce seu poder sobre Péricles não apenas pelas suas qualidades femininas, mas também por seus atributos intelectuais, as demais cortesãs apresentadas tiram proveito mais de sua beleza física. Nosso autor descreve as cortesãs como mulheres voluntariosas que não medem esforços para a realização de seus caprichos, além de deterem grande poder sobre seus amantes e as cidades que governam. Em contrapartida, Plutarco também nos mostra que alguns homens aproveitaram essa ascensão que as cortesãs tinham sobre governantes e líderes militares para manipulá-las, obtendo benefícios com essa relação.

Aspásia de Mileto $^{20}$ surge como a personagem 
feminina mais importante na biografia de Péricles; segundo Plutarco, acreditava-se que ela tinha forte ascendência sobre as açôes do governante ateniense. Assim, Péricles teria organizado uma expedição militar contra Samos para cessar sua guerra contra Mileto, a cidade natal de sua amada. Nosso autor afirma que Aspásia concorria com Targélia, uma cortesão da Jônia, que influenciou muitos governantes e filósofos, o que inspirou a cortesã de Mileto a fazer o mesmo. No entanto, havia uma diferença entre elas: Targélia, ao unir-se aos mais poderosos, conseguia impor-se pela força deles, já a cortesão milésia influenciava Péricles porque era

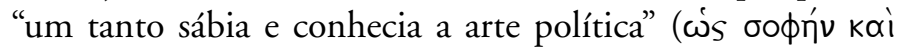
полıтıкі̀v). Plutarco relata ainda que Sócrates costumava frequentar a casa de Aspásia, que por sua vez formava novas cortesãs, mas o curioso é que as esposas de seus amigos íntimos também frequentavam a sua casa. No entanto, tamanho poder de Aspásia sobre as decisões do político ateniense se explica pelo amor que este nutria por ela, ${ }^{21}$ pois, conforme afirma Plutarco "parece, todavia, que a afeição

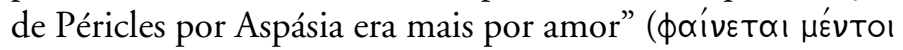

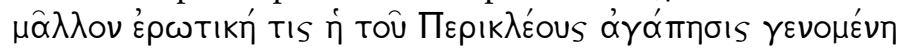

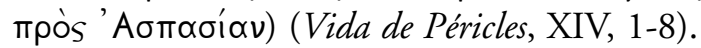

Durante os preparativos de sua guerra contra Dario, ${ }^{22}$ Alexandre organiza um banquete com muitas cortesãs, sendo Taís era a mais famosa delas. Conforme Plutarco, a cortesã ateniense era amante de Ptolomeu e muito influente entre os soldados, a ponto de discursar para animá-los a combater com todo empenho, discurso que foi vivamente aplaudido pelos presentes. Em suas palavras, Taís afirmara que os macedônios compensariam suas perambulaçōes pela Ásia, assim como vingariam a sua cidade natal pelo incêndio provocado por Xerxes (Vida de Alexandre, XXXVIII, 1-6).

$\mathrm{Na}$ biografia de Fócion, Plutarco conta que um certo Harpálo apaixonou-se por uma cortesã chamada Fitonice e que, após a sua morte, erigiu um suntuoso túmulo para a sua amante, gastando trinta talentos na construção do monumento (Vida de Fócion, XXII, 1-2).

Demétrio envolveu-se com a cortesã ateniense Lâmia, a quem Plutarco afirma que ele entregou a quantia de duzentos e cinquenta talentos, fato que desagradou em muito os atenienses. E nosso autor segue seu relato descrevendo
20. Para a contribuição de Aspásia para a história da retórica na Grécia antiga, consultar: Glenn: 1994, 180-199.

21. Aspásia se relacionou com Péricles em um período em que as leis de cidadania em Atenas eram muito rígidas; talvez isso explique parte do preconceito percebido contra ela na escrita dos autores gregos dessa época, em especial, os cômicos. A respeito dessas leis atenienses, consultar: Osborne: 1997, 3-33.

22. Cagnazzi nos informa que "L'aggettivo $\mu$ '́ $\gamma \alpha_{S}$ accanto al nome di Alessandro sembra essere stato utilizzato per la prima volta da Efippo di Olinto, uno degli, storici di Alessandro (FGrHist 126), contemporaneo del giovane re e piu attento alla trasformazione del cerimoniale di corte sotto l'influsso della monarchia persiana, all'indomani della sconfitta di Dario III nella battaglia di Gaugamela, il 1 ottobre del 331" (Cagnazzi: 2005, 132). 
cenas de ciúme e de conquista ocorridas entre Lâmia e Demétrio em um suntuoso banquete, assim como relatando cenas em que ela demonstra o seu poder sobre ele (Vida de Demétrio, XXVII, 1-14).

Plutarco relata que em Roma houve Flora, uma cortesã que em sua velhice conservava boas lembranças de Pompeu, que ela se recusara a fazer um bom casamento para permanecer fiel aos bons tempos que passara ao lado do general romano (Vida de Pompeu, II, 3).

Nosso autor nos relata ainda que, para obter vantagem estratégica na acirrada guerra contra Mitridates, Luculo cooptou a bela Précia, uma cortesã persuasiva e influente da Cilícia, regiāo vizinha à Capadócia, pois ela exercia grande influência entre os comandantes locais. No entanto, quando Luculo obteve o poder necessário na região, ele a ignorou (Vida de Luculo, VI, 3-5). ${ }^{23}$

\section{AS INFIÉIS}

23. Para uma análise mais aprofundada da biografia de Luculo, consultar: Lavery: 1994, 261-273.
Mulheres infiéis também figuram na narrativa biográfica de Plutarco, mas é curioso perceber que algumas traíram seus companheiros de bom grado, mas outras parecem ter sido acusadas de traição por conveniência, embora nosso autor não se pronuncie abertamente sobre essa possibilidade. Contudo, quando um biografado alega traição, Plutarco logo conta que esse contrai matrimônio em seguida, às vezes, com uma mulher mais rica ou mais jovem, como se o ato de repudiar uma mulher também fosse utilizado como uma manobra do homem para estabelecer novas alianças.

Após sofrer diversos reveses políticos e militares em Atenas, Alcibíades se refugia em Esparta e lá seduz Timeia, a esposa do rei Ágis, com quem tem um filho chamado Leotíquidas (Vida de Alcibiades, XXIII, 7), acontecimento que Plutarco registra também na biografia de Agesilau (Vida de Agesilau, III, 1).

Júlio César era casado com Pompeia, por quem Públio Clódio era apaixonado; segundo Plutarco, a mulher não lhe era indiferente, mas a mãe de Júlio César fazia-lhe a vigilância, impedindo a aproximação dos dois. Como Pompeia era a 
responsável daquele ano pela organização da Gineceia, um festival exclusivamente feminino, Clódio, um jovem rapaz ainda, planejou participar do festival trajando-se de mulher, então fingindo ser uma tocadora de harpa. No entanto, ele foi descoberto por uma serva e seu nome foi difamado por toda a cidade, sob a alegação de ter cometido um ato sacrílego ao violar a cerimônia considerada sagrada. Um dos tribunos da plebe o processou por impiedade, sendo acusado ainda de uma relação incestuosa com sua irmã, mulher de Luculo. Tal processo serviu de argumento para que Júlio César repudiasse Pompeia, ao passo que Clódio foi absolvido (Vida de César, IX, 3-8 e X, 1-11). ${ }^{24}$

Catão, o Jovem desposou Atília, filha de Serrano, mas ela não foi a sua única mulher, ${ }^{25}$ e Plutarco acrescenta "como Laio, companheiro de Cipião; mas aquele foi o mais afortunado, nos muitos anos vividos, teve uma única mulher com quem se casou desde quando a conheceu ( $k \alpha \theta \alpha$ пा $\rho$

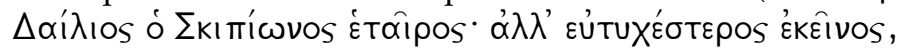

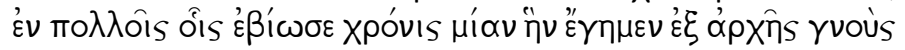
үuvôika) (Vida de Catão, 7, 3). Atília foi repudiada por Catão que a acusava de traição, em seguida ele desposou Márcia, filha de Filipo (XXIV, 6 e XXV, 1).

\section{As CONVENIENTES}

Plutarco nos mostra que as mulheres, por seus laços de parentesco e suas riquezas, eram importantes às aspiraçôes políticas e econômicas dos homens. O modo mais comum de obtenção desses privilégios então era o casamento com uma mulher de origem nobre; ${ }^{26}$ por isso era uma mulher conveniente para se estabelecer uma união proveitosa.

O casamento de Alcibíades é descrito por Plutarco como uma manobra do ateniense para iniciar a sua carreira política, pois sua esposa era filha de Hipônico, homem "com grande

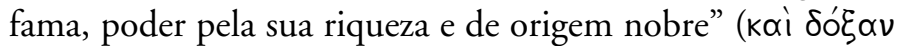

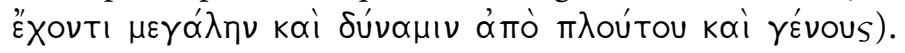
Hipareta, a esposa de Alcibíades, é apresentada como uma mulher infeliz no casamento que tenta, sem sucesso, a dissolução de sua união matrimonial junto ao arconte, sob a alegação de que seu esposo somente frequentava as cortesãs.
24. Plutarco também conta esse episódio na Vida de Cícero, XXVIII, $1-4$.

25. Para mais informações sobre as esposas e a família de Catão, o Jovem, consultar: Means \& Dickison: 1974, 210-215.

26. A respeito do casamento como uma transação financeira, consultar: Lyons: 2003, 93-134. 
27. A respeito da imagem que Plutarco faz de Demétrio, consultar: Tatum: 1996, 135-151.
Apesar disso, Hipareta gostava de seu marido e lhe tinha devoção, e se manteve casada com Alcibíades até a morte de seu marido em Éfeso (Vida de Alcibiades, VIII, 1-6).

"Por pragmatismo e mais poder, desposou muitas

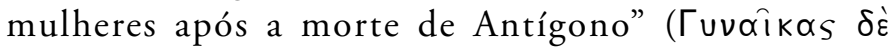

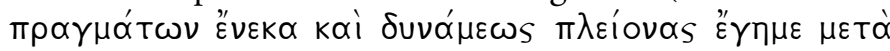

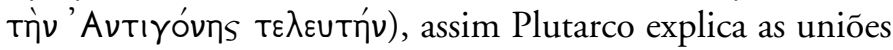
de Pirro; sem dizer o nome da primeira, afirma que se casou com a filha de Audoleonte, rei dos peônios; Bircena, filha do rei dos ilírios e Lanassa, filha de Agatócles, que lhe trouxe como dote a cidade de Corcira (Vida de Pirro, XIX, 1-2).

Alexandre envolveu-se com Roxane após um festim, encontro que resultou em casamento. De acordo com Plutarco, Alexandre tinha interesse de se unir a ela para concretizar mais um de seus projetos. $\mathrm{O}$ seu intento era conquistar a confiança dos bárbaros, plano que funcionou, dado que passaram a olhá-lo com mais simpatia por haver desposado uma mulher da Báctria. Nosso autor destaca ainda que Roxane foi a única mulher que despertou o interesse de Alexandre e que ele

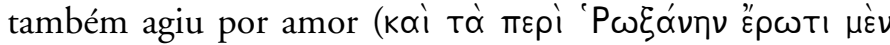
$\varepsilon \pi \rho \alpha ́ x \theta \eta$ ) (Vida de Alexandre, XLVIII, 7-8). Apesar disso, ao vencer a batalha contra Dario, Alexandre desposa sua filha, Estatira, celebrando suas núpcias em Susa (LXX, 3).

Nosso autor conta que Demétrio foi casado com várias mulheres ao mesmo tempo, mas que prezava apenas uma: Fila, filha de Antípatro, por ela ter antes desposado Crátero, o sucessor de Alexandre, honrado pelos macedônios; e acrescenta que Demétrio era muito jovem e Fila era muito mais velha, e ainda que o casamento foi uma imposição de seu pai (Vida de Demétrio, XIV, 2-3). Seleuco articulou um casamento de seu filho com a filha de Demétrio e Fila, Estratonice; sua finalidade era de anexar mais territórios aos seus e expandir o seu poder (XXXI, 5-6). ${ }^{27}$

Quando instituído o seu reinado, Rômulo promove o rapto das sabinas (Vida de Rômulo, XIV, XV e XVI) para a fusão dos povos, e Plutarco descarta uma relação afetiva entre Rômulo e Hersília ${ }^{28}$ relatada por Zenódoto de Trezena (XIV, 7-8).

Plutarco relata que Paulo Emílio desposou Papíria, filha de Masão, com quem teve dois filhos, Cipião e Fábio Máximo, 
romanos ilustres. No entanto, sem detalhar os motivos, nosso autor afirma que, após muitos anos de casamento, Paulo Emílio repudia Papíria e entrega suas filhas em casamento, uma para o filho de Catão e a outra para Élio Túbero, ambos de famílias notáveis; e ainda nos esclarece que Cipião e Fábio Máximo foram entregues à adoção para as famílias homônimas (Vida de Paulo Emilio, V, 1-8).

Sula, nas palavras de nosso autor, também realizou um casamento brilhante ao se unir à Cecília, filha do pontífice máximo Metelo. No entanto, ela era a sua quarta esposa, antes havia se casado com Ília, Élia e Clélia, esta última repudiada por esterilidade (Vida de Sula, VI, 10-12). Em outra ocasião, quando foi assistir a um espetáculo de gladiadores, Sula sentou-se ao lado de Valéria, uma mulher de grande beleza e de nobre família; após trocar muitos olhares e sorrisos, resolveu desposá-la. Plutarco descreve assim o encontro dos dois: primeiro, ela passou por Sula e lhe tirou um fiapo de sua túnica, então ele se virou e ouviu dela que queria apenas ter um pouco da sorte que o acompanhava, isso à época em que era permitido que homens e mulheres sentassem juntos no teatro (XXXV, 3-5).

Segundo nosso autor, Luculo desposou duas romanas: Clódia, que "por ser licenciosa e maldosa" (oüons ảoc $\lambda$ yoûs кরi тоvпрâs), ele a abandonou, e Servília, irmã de Catão, sobre a qual recaía a "acusação de ser incestuosa com o irmão; quanto ao resto, era igualmente repugnante" ( $\dot{\eta} \dot{\varepsilon} \pi \dot{i} \tau \hat{\omega}$

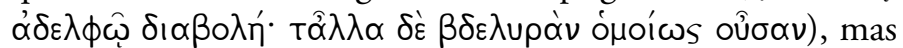
Luculo a suportava porque era irmã de Catão (Vida de Luculo, XXXVIII, 1).

Júlio César entregou sua filha Júlia a Pompeu e desposou Calpúrnia, filha de Pisão, e com seu apoio ele foi eleito cônsul, sob o protesto de Catão que acusava Júlio César de usar o expediente do casamento para obter cargos públicos (Vida de César, XIV, 8-10).

Plutarco conta que Cícero dispunha de várias propriedades, de uma considerável herança e ainda de um dote valioso de sua esposa Terência; "por isso, com liberdade e moderação, passava o tempo convivendo com os literatos

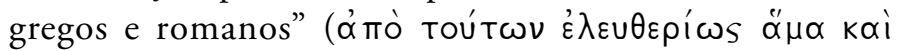

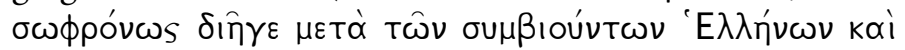

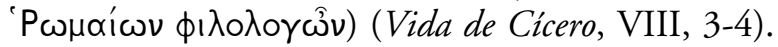

28. Wiseman analisa esse fragmento de Zenódoto de Trezena citado por Plutarco, comparando-o com outros autores; consultar: Wiseman: 1983, 445-452. 
$\mathrm{Na}$ biografia de Teseu, duas personagens femininas se relacionam casualmente com o herói: são mulheres que ele encontra durante suas jornadas; dessas relações nascem alguns filhos. Plutarco não nos traz detalhes sobre o destino dessas crianças, mas podemos inferir que suas mães as criaram sozinhas.

Durante a sua jornada, Teseu foi eliminando os seres monstruosos que impediam a circulação dos viajantes, mas um especial, Sínis, chama a atenção por conta de Períone, sua filha, com quem Teseu manterá relações sexuais, após eliminá-lo, e dela nascerá seu filho Melanipo, que será o pai de Ioxo, o herói fundador da Cária (Vida de Teseu, VIII, 4-5). Na luta contra as Amazonas, uma em particular, Antíope ou Hipólita, desperta a paixão de Teseu com que gerará Hipólito, personagem da famosa peça homônima de Eurípides (XXVI e XXVII). ${ }^{29}$

29. Outros nomes femininos surgem, mas de menor importância, pois são apenas relacionamentos amorosos que não resultam em filhos ilustres. Há ainda um breve relato sobre a mítica história do rapto de

Helena e a busca dos

Dióscuros, quando, segundo Plutarco, Teseu já havia completado cinquenta anos; talvez esse dado sirva para explicar sua derrota para os irmãos gêmeos de Helena (XXXI).

30. Sobre a associação que Plutarco faz de Ariadne com Afrodite, consultar: Cueva: 1996, 473-484.

31. Sobre as várias versões do destino de Ariadne, a de Plutarco inclusive, ler o vigésimo capítulo dessa biografia.

\section{AS APAIXONADAS}

Encontramos duas mulheres que se preocuparam com o destino de seus companheiros, ajudando-os dentro de suas possibilidades. A primeira é Ariadne, ${ }^{30}$ a filha do rei Minos, a terceira personagem feminina de destaque na Vida de Teseu, que se enamora por ele. Graças à sua intervenção, o herói consegue derrotar o Minotauro e vencer os caminhos sinuosos do Labirinto de Creta (Vida de Teseu, XIX, 1-6). ${ }^{31}$

Bruto era filho de Servília, irmã de Catão; depois seu tio tornou-se seu genro (Vida de Bruto, II, 1). Plutarco afirma que César agradava Servília, que era muito apaixonada por ele, por imaginar que Bruto era seu filho natural (V, 1-4). O nome de Pórcia, a filha de Catão, que Plutarco descreve como uma mulher amorosa e atenciosa com seu marido, surge quando Bruto está angustiado com o seu segredo e ela o estimula a seguir em frente com seu plano de assassinar César (XIII, 3-11). O nome dela reaparece no dia do assassinato, descrita como ansiosa e muito nervosa após Bruto sair para cumprir sua missão (XV, 6-7), e novamente nas últimas linhas 
da biografia de Bruto, quando Plutarco conjectura sobre o sofrimento de Pórcia com a morte do marido (LIII, 6-7).

\section{CONClusốes}

As mulheres aparecem nas biografias plutarquianas como um grupo dependente da história de suas personagens masculinas. No entanto, não podemos considerar que elas ocupem um lugar marginal em sua narrativa, pois, como vimos, há momentos em que elas são decisivas. Assim, a condição dessas mulheres resulta em um papel econômico, social e político muito distinto do reservado aos homens, porém as mulheres não desempenham uma posição marginal ou submissa na narrativa de Plutarco. Nem ao menos percebemos em seu discurso uma mentalidade misógina, embora tenhamos características notadamente femininas como seu instinto de proteção de sua prole ou de sua pólis. É interessante perceber ainda que Plutarco não trata as mulheres como um grupo homogêneo, nem nos traz a imagem de uma sociedade em que há a segregação do feminino; pelo contrário, vemos uma integração entre o feminino e o masculino. Sob outra perspectiva, Plutarco também não nos apresenta uma sociedade matriarcal.

Apesar de não participar diretamente da vida política da cidade, a mulher integra o jogo político, ela é uma peça importante neste tabuleiro: o casamento surge como um expediente masculino para sua projeção social. Contudo, notamos que é através da legislação que o universo feminino se limita, com as leis que permitem o repúdio da companheira que favorecem o homem, tornando-o livre para desposar quantas mulheres lhe for conveniente. No entanto, esse jogo não reduz a mulher ao anonimato; ela se faz ver nos atos religiosos, nos adultérios, nas cenas de resistências, quando denuncia seu violador ou defende sua cidade do ataque inimigo. Em suma, Plutarco não revela um mundo em que há antagonismo, segregação ou conflito entre os gêneros; o que notamos é a integração entre eles: ainda que estejam em condições de desiguais, tais diferenças revelam que cada um tem o seu papel a desempenhar na sociedade. Portanto, visto que as sociedades são heterogêneas e seus 
contextos históricos também são distintos, Plutarco nos mostra mulheres com perfis muito diferentes, sem mostrálas apenas sob um ponto de vista.

\section{REFERÊNCIAS BiBLIOGRÁFICAS}

\section{EDIÇŌES}

PLUTARCH. Life of Aemilius Paulus. Lives. Vol. VI. Translated by Bernadotte Perrin. Cambridge/Massachusetts/ London, Harvard University Press, 2005.

. Life of Agesilaus. Lives. Vol. V. Translated by Bernadotte Perrin. Cambridge/Massachusetts/London, Harvard University Press, 2004.

Life of Agis. Lives. Vol. X. Translated by Bernadotte Perrin. Cambridge/Massachusetts/London, Harvard University Press, 2001.

Life of Alexander. Lives. Vol. VII. Translated by Bernadotte Perrin. Cambridge/Massachusetts/London, Harvard University Press, 2004.

. Life of Antony. Lives. Vol. IX. Translated by Bernadotte Perrin. Cambridge/Massachusetts/London, Harvard University Press, 2005.

Life of Artaxerxes. Lives. Vol. XI. Translated by Bernadotte Perrin. Cambridge/Massachusetts/London, Harvard University Press, 2002.

Life of Aratus. Lives. Vol. XI. Translated by Bernadotte Perrin. Cambridge/Massachusetts/London, Harvard University Press, 2002.

Life of Brutus. Lives. Vol. VI. Translated by Bernadotte Perrin. Cambridge/Massachusetts/London, Harvard University Press, 2005.

. Life of Cato the Younger. Lives. Vol. VIII. Translated by Bernadotte Perrin. Cambridge/Massachusetts/London, Harvard University Press, 2004.

. Life of Cicero. Lives. Vol. VII. Translated by 
Bernadotte Perrin. Cambridge/Massachusetts/London, Harvard University Press, 2004.

. Life of Cleomenes. Lives. Vol. X. Translated by Bernadotte Perrin. Cambridge/Massachusetts/London, Harvard University Press, 2001.

. Life of Coriolanus. Lives. Vol. IV. Translated by Bernadotte Perrin. Cambridge/Massachusetts/London, Harvard University Press, 2006.

. Life of Demetrius. Lives. Vol. IX. Translated by Bernadotte Perrin. Cambridge/Massachusetts/London, Harvard University Press, 2005.

Life of Julius Caesar. Lives. Vol. VII. Translated by Bernadotte Perrin. Cambridge/Massachusetts/London, Harvard University Press, 2004.

Life of Lucullus. Lives. Vol. II. Translated by Bernadotte Perrin. Cambridge/Massachusetts/London, Harvard University Press, 2006.

. Life of Lycurgus. Lives I. Translated by Bernadotte Perrin. Cambridge/Massachusetts/London, Harvard University Press, 2005.

. Life of Marcellus. Lives. Vol. V. Translated by Bernadotte Perrin. Cambridge/Massachusetts/London, Harvard University Press, 2004.

- Life of Pericles. Lives. Vol. III. Translated by Bernadotte Perrin. Cambridge/Massachusetts/London, Harvard University Press, 2002.

Life of Pelopidas. Lives. Vol. V. Translated by Bernadotte Perrin. Cambridge/Massachusetts/London, Harvard University Press, 2004.

Life of Phocion. Lives. Vol. VIII. Translated by Bernadotte Perrin. Cambridge/Massachusetts/London, Harvard University Press, 2004.

- Life of Pompey. Lives. Vol. V. Translated by Bernadotte Perrin. Cambridge/Massachusetts/London, Harvard University Press, 2004. 
Life of Publicola. Lives. Vol. I. Translated by Bernadotte Perrin. Cambridge/Massachusetts/London, Harvard University Press, 2005.

Life of Pyrrhus. Lives. Vol. IX. Translated by Bernadotte Perrin. Cambridge/Massachusetts/London, Harvard University Press, 2005.

Life of Romulus. Lives. Vol. I. Translated by

Bernadotte Perrin. Cambridge/Massachusetts/London, Harvard University Press, 2005.

Life of Sulla. Lives. Vol. IV. Translated by Bernadotte Perrin. Cambridge/Massachusetts/London, Harvard University Press, 2006.

- Life of Theseus. Lives. Vol. I. Translated by Bernadotte Perrin. Cambridge/Massachusetts/London, Harvard University Press, 2005.

\section{LIVROS, ARTIGOS E CAPÍTULOS DE LIVRO}

BREMMER, J. "Plutarch and the Naming of Greek Women”. The American Journal of Philology, vol. 102, n. 4, 1981, pp. 425-426.

BUSZARD, B. "The Speech of Greek and Roman Women in Plutarch's Lives”. Classical Philology, vol. 105, n. 1, 2010, pp. 83-115.

CAGNAZZI, S. "Il grande Alessandro". Zeitschrift für Alte Geschichte, Bd. 54, H. 2, 2005, p. 132-143.

CARAWAN, E. M. “The Tragic History of Marcellus and Livy's Characterization”. The Classical Journal, vol. 80, n. 2, 1984-1985, pp. 131-141.

CUEVA, E. P. "Plutarch's Ariadne in Chariton's Chaereas and Callirhoe". The American Journal of Philology, vol. 117, n. 3, 1996, pp. 473-484.

GLENN, C. "Sex, Lies, and Manuscript: Refiguring Aspasia in the History of Rhetoric". College Composition and Communication, vol. 45, n. 2, 1994, pp. 180-199. 
HUZAR, E. G. "Mark Antony: Marriages vs. Careers". The Classical Journal, vol. 81, n. 2, 1985-1986, pp. 97-111.

JACQUIM, C. "Woman between the Tyrant and the Polis: The Role of Women in Tyrannical Regimes", Classic@: An Online Journal, Homepage: http://chs.harvard.edu/wa/ pageR?tn=ArticleWrapper\&bdc=12\&mn=1304, 2011, 1-22.

Gerard B. Lavery, "Plutarch's Lucullus and the Living Bond of Biography", The Classical Journal, vol. 89, 3, 1994, pp. 261-273.

LE CORSU, F. Plutarque et les femmes dans les Vies paralleles. Paris: Les Belles Lettres, 1981.

LYONS, D. "Dangerous Gifts: Ideologies of Marriage and Exchange in Ancient Greece", Classical Antiquity, vol. 22, n. 1, 2003, pp. 93-134.

LOMAN, P. “No Woman No War: Women's Participation in Ancient Greek Warfare”. Greece \& Rome, vol. 51, n. 1, 2004, pp. 34-54.

MARASCO, G. "Cleopatra e gli esperimenti su cavie umane". Zeitschrift für Alte Geschichte, Bd. 44, H. 3, 1995, pp. 317-325.

MEANS, T. \& DICKISON, S. K. "Plutarch and the Family of Cato Minor". The Classical Journal, vol. 69, n. 3, 1974, pp. 210-215.

MOSSÉ, C. "Women in teh Spartan Revolution of the Third Century B.C.”, in: Women's History \& Ancient History, Sarah B. Pomeroy (ed.), Chapel Hill/New York, The University of North Carolina Press, 1991, pp. 138-153.

MOSSMAN, J. "Taxis Ou Barbaros: Greek and Roman in Plutarch's Pyrrhus". The Classical Quarterly, vol. 55, n. 2, 2005, pp. 498-517.

" "Tragedy and Epic in Plutarch's Alexander". The Journal of Hellenic Studies, vol. 108, 1988, pp. 83-93.

OSBORNE, R. "Law, the Democratic Citizen and the Representation of Women in Classical Athens". Past \& Present, n. 155, 1997, pp. 3-33. 
POMEROY, S. B. Goddesses, Whores, Wives, and Slaves. Women in Classical Antiquity, New York, Schoken Books, 1995.

RUSSELL, D. A. "Plutarch and the Antique Hero". The Yearbook of English Studies, vol. 12, Heroes and the Heroic Special Number, 1982, pp. 24-34.

. "Plutarch's Life of Coriolanus". The Journal of Roman Studies, vol. 53, 1963, pp. 21-28.

REDFIELD, J. "The Women of Sparta". The Classical Journal, vol. 73, n. 2, 1977-1978, pp. 146-161.

SILVA, M. A. O. Plutarco Historiador: Análise das Biografias Espartanas. São Paulo, Edusp, 2006.

TATUM, W. J. “The Regal Image in Plutarch's Lives”, The Journal of Hellenic Studies, vol. 116, 1996, pp. 135-151.

WALCOT, P. "Plutarch on Sex". Greece \& Rome, vol. 45, n. 2, 1998, pp. 166-187.

WET, B. X. "Contemporary Sources in Plutarch's Life of Antony”. Hermes, 118. Bd., H. 1, 1990, pp. 80-90.

WISEMAN, T. P. "The Wife and Children of Romulus", The Classical Quarterly, vol. 33, n. 2, 1983, pp. 445-452.

Enviado em janeiro de 2014 Aprovado em abril de 2014. 